\title{
LIETUVOS SLIDININKŲ IR BIATLONININKŲ FIZINIŲ BEI FUNKCINIŲ GALIŲ SĄSAJA IR JŲ LYGINAMOJI ANALIZE்
}

\author{
Stanislav Sabaliauskas, Kazys Milašius \\ Vilniaus pedagoginis universitetas, Vilnius, Lietuva
}

\begin{abstract}
Stanislav Sabaliauskas. Socialinių mokslų magistras. Vilniaus pedagoginio universiteto Sporto metodikos katedros asistentas, VPU doktorantas. Lietuvos biatlono rinktinès treneris. Mokslinių tyrimų kryptis - didelio meistriškumo slidininkų ir biatlonininkų sporto treniruotės ir jų rengimo valdymas.
\end{abstract}

\section{SANTRAUKA}

Viena iš aktualesniu sportininku fiziniu ir funkciniu galiu diagnostikos problemu yra adekvatus sportininku specialiojo darbingumo ir funkciniu galiu ivertinimas kiekvienu pasirengimo laikotarpiu. Slidininku ir biatlonininku organizmo fizinio darbingumo ir funkciniu galiu rodikliu vertinimas sietinas su fizinio išsivystymo rodikliais. Šiu rodikliu tarpusavio sqsajos analize išryškina ypatybes, kurios yra labai reikšmingos slidininkams ir biatlonininkams, siekiantiems puikiu rezultatu.

Tyrimo tikslas - iširti Lietuvos slidininku ir biatlonininku fizinio išsivystymo, fiziniu gebèjimu, kai kuriu funkciju bruožus, atlikti ju lyginamaja analizę ir nustatyti tarpusavio ryšius.

Tyrimo metodai: nustatyti pagrindiniai fizinio išsivystymo rodikliai, fizinis pajègumas vertintas pagal absoliutu ir santykini vienkartini raumenu susitraukimo galinguma, anaerobini alaktatini galinguma, anaerobini glikolitini pajéguma ir aerobini pajéguma. Tyrimu medžiaga apdorota matematinès statistikos metodais.

Nustatyta, kad tarp sportininku bendrosios kūno, raumenu masès ir raumenu galingumo, atliekant ivvairios trukmès krūvì, yra glaudūs koreliaciniai ryšiai. Raumenu masè turi tiesioginius patikimus ryšius su absoliučiuoju vienkartiniu raumenu susitraukimo galinguти $(V R S G)(r=0,705)(p<0,01)$ ir anaerobiniu alaktatiniu raumenu galingumu $(A A R G)(r=0,643)(p<0,01)$. Atlikto tyrimu duomenys taip pat rodo glaudu koreliacini ryši tarp VRSG ir AARG $(r=0,701)$ ir labai glaudu AARG ir $10 s$ trukmés darbo galingumo $(r=0,851)(p<0,001)$ ryšs. Nustatyta, kad esant mažai tiriamuju kūno masès sklaidai $(V=9,7 \%)$ patikimo koreliacinio ryšio tarp kūno masès ir $V O_{2 \max }$ nèra $(r=0,401)(p>0,05)$. Tarp $V_{2} O_{2 \max }$ ir deguonies suvartojimo ties anaerobinio slenksčio riba buvo stiprus koreliacinis ryšys $(r=0,743)(p<0,001)$.

Apibendrinant tyrimo duomenis galima pažymèti, kad Lietuvos slidininku ir biatlonininku fiziniu bei funkciniu galiu rodikliai yra daugiau vidutinio lygio, lyginant juos su kitu šaliu pajègiausiuju žiemos šaku sportininku duomenimis. Todè šio tyrimo metu gauta informacija gali padèti tobulinti tolimesní Lietuvos slidininku ir biatlonininku rengima, didinti ju fizines bei funkcines galias, ugdyti jas reikiama kryptimi.

Raktažodžiai: fizinis išsivystymas, fizinès galios, koreliacijos koeficientas.

\section{IVADAS}

$\mathrm{S}$ lidinejimo ir biatlono raidos tendencijos pasaulyje skatina vis labiau pažinti, tobulinti ir optimizuoti sportininkų rengimą (Hottenrott, Urban, 1998; Čepulènas, 2001; Rusko, 2003). Slidinejimo lenktyniu ir biatlono specifika, pratybų ir varžybų krūviai kelia panašius reikalavimus sportininkų organizmui, nors siauresnę kurios nors rungties specializaciją sportininkai pasirenka tik pasiekę dideli sportinį meistriškumą (Bergh Forsberg, 1992; Grashill et al., 1999; Čepulènas, 2004). Tokių sportininkų rezultatus daug lemia genetiniai požy- miai, organizme vykstančiu adaptacinių pokyčiu kryptis ir ju intensyvumas (Bompa, 1994; Byrnes, Kearnary, 1997; Grund et al., 2001; Mäestu et al., 2005; Tubelis ir kt., 2006). Viena iš aktualesnių sportininkų fizinių ir funkciniu galių diagnostikos problemų yra adekvatus sportininkų specialiojo darbingumo ivertinimas kiekvienu pasirengimo laikotarpiu. Slidininkų ir biatlonininkų organizmo fizinio darbingumo ir funkcinių galių rodiklių vertinimas sietinas su fizinio išsivystymo rodikliais (Street, Gregory, 1994; Čepulènas, 2004; Tubelis 
ir kt., 2006). Šių rodiklių tarpusavio sąsajos analizè išryškina ypatybes, kurios yra labai reikšmingos slidininkams ir biatlonininkams, siekiantiems puikių rezultatu. Nors Lietuvoje yra sukaupta nemaža didelio meistriškumo slidininku ir biatlonininkų rengimo patirtis (Čepulènas, 1997, 2001; Milašius ir kt., 1998), tačiau mokslo darbuose dar nepakanka informacijos, apibūdinančios slidininkų ir biatlonininkų organizmo sistemų funkcini pajègumą bei fizinių ir funkcinių galių sąsają. Todèl išlieka aktualu atlikti slidininkų ir biatlonininkų fizinių, funkcinių galių lyginamają analizę, nustatyti jų tarpusavio koreliacinius ryšius.

Tyrimo tikslas - iširti Lietuvos slidininkų ir biatlonininkų fizinio išsivystymo, fiziniu gebejjimu, kai kurių funkcijų bruožus, atlikti jų lyginamają analizę ir nustatyti tarpusavio koreliacinius ryšius.

\section{TYRIMO ORGANIZAVIMAS IR METODAI}

2004-2006 metais ištirta 15 Lietuvos pajëgiausių slidininkų ir biatlonininkų, kurių amžius - nuo 17 iki 24 metú. Nustatyti pagrindiniai fizinio išsivystymo rodikliai - ūgis, kūno masè, raumenu ir riebalų masè, dešinès ir kairès plaštakos jèga, gyvybinè plaučiu talpa (GPT). Fizinis pajègumas vertintas pagal absoliutu ir santykinị vienkartini raumenų susitraukimo galingumą (VRSG) (Bosco, 1982), anaerobini alaktatini raumenų galingumą (AARG) (Margaria, 1966) ir $10 \mathrm{~s}$ trukmès anaerobini alaktatini darbą, atlikta veloergometru. Anaerobinis glikolitinis pajëgumas (AGP) nustatytas atlikus 1 min trukmès darbą maksimaliomis pastangomis veloergometru (Szögy, Cherebetin, 1979). Aerobinis pajègumas tirtas duju analizatoriumi ERGOOXSKREEN. Ties kritinio intensyvumo riba (KIR) ir anaerobinio slenksčio riba (ANS) nustatyta plaučių ventiliacija $(\mathrm{PV})$, pulso dažnis $(\mathrm{PD})$, maksimalusis deguonies suvartojimas $\left(\mathrm{VO}_{2 \max }\right)$ ir deguonies suvartojimas ties anaerobinio slenksčio riba $\left(\mathrm{VO}_{2}\right)$, atliekamo darbo galingumas (W) (Nowacki, 1978).

Kraujotakos ir kvėpavimo sistemos funkcinis pajègumas ivvertintas Rufjè indekso testu. Visų šių tyrimu metodika aprašyta J. Skernevičiaus ir kt. (2004) vadovélyje „Sporto mokslo tyrimų metodologija“. Tyrimų analizei atlikti taikyti matematinès statistikos metodai: apskaičiuoti aritmetiniai vidurkiai $(\bar{x})$, reprezentacinès jų paklaidos $(S \bar{x})$, standartiniai nuokrypiai (S), variacijos koeficientai (V). Imties sklaidos plotui išreikšti pateiktos mažiausios (min.) ir didžiausios (maks.) rodiklių reikšmès. Ryšio patikimumo laipsnis ir reikšmingumas buvo vertinamas taip: $\mathrm{p}<0,05$, kai $\mathrm{r}=0,497-0,605 ; \mathrm{p}<0,01$, kai $\mathrm{r}=0,606-0,715$; $\mathrm{p}<0,001$, kai $\mathrm{r}=0,716$ ir daugiau.

\section{REZULTATAI}

Analizuojant fizinio išsivystymo rodiklius (1 lent.) matyti, kad sportininkų ūgio ir kūno masès rodiklių sklaida nedidele ( $\mathrm{V}=2,3$ ir $\mathrm{V}=9,7 \%)$, nors kūno masès sklaidos plotas siekè $21,5 \mathrm{~kg}$. Gana didelè yra riebalų masès sklaida ( $V=20,3 \%)$, o sklaidos plotas siekia 5,5 kg. Dar didesnè sklaida pastebèta analizuojant raumenų ir riebalų masès indekso rodikli $(\mathrm{V}=25,1 \%)$. Slidininkų ir biatlonininkų fizinio išsivystymo rodiklių nustatymas bei ịvertinimas yra svarbus rengiant šių šakų sportininkus.

Sportininkų VRSG buvo lygus vidutiniškai $25,2 \pm 1,0 \mathrm{~W} / \mathrm{kg}$, sklaidos procentine išraiška siekè 15,6\%. Tiriamujų sportininkų AARG vidutiniškai sieké $16,7 \pm 0,3 \mathrm{~W} / \mathrm{kg}$. Šio rodiklio sklaida nedidelè (V=6,6\%) (2 lent.). Lietuvos slidininku ir biatlonininku $10 \mathrm{~s}$ trukmès darbo anaerobinis alaktatinis absoliutus galingumas siekia vidutiniškai $878,1 \pm 33,8 \mathrm{~W}$, o santykinis $11,7 \pm 0,3 \mathrm{~W} / \mathrm{kg}$. Šio rodiklio sklaida nedidele $(\mathrm{V}=8,6 \%)$. Slidininkų ir biatlonininku anaerobinis glikolitinis pajègumas yra vienas iš svarbiausių fizinès galios rodiklių (2 lent.). Tirtų Lietu-

\begin{tabular}{|c|c|c|c|c|c|c|c|c|}
\hline \multirow{2}{*}{ Rodikliai } & \multirow{2}{*}{ Ūgis, cm } & \multirow{2}{*}{ Kūno masè, kg } & \multicolumn{2}{|c|}{ Plaštakų jèga, kg } & \multirow{2}{*}{ GPT, I } & \multirow{2}{*}{$\begin{array}{c}\text { Raumenų } \\
\text { masė, kg }\end{array}$} & \multirow{2}{*}{$\begin{array}{l}\text { Riebalụ } \\
\text { masė, kg }\end{array}$} & \multirow{2}{*}{ RRMI } \\
\hline & & & D & $\mathbf{K}$ & & & & \\
\hline$\overline{\mathrm{x}}$ & 183,4 & 74,2 & 47,7 & 45,6 & 5,0 & 40,1 & 6,8 & 6,1 \\
\hline $\mathrm{S} \overline{\mathrm{x}}$ & 1,1 & 1,9 & 1,5 & 1,9 & 0,2 & 1,2 & 0,4 & 0,4 \\
\hline $\mathrm{S}$ & 4,2 & 7,2 & 5,7 & 7,5 & 0,6 & 4,6 & 1,4 & 1,5 \\
\hline $\mathrm{V}, \%$ & 2,3 & 9,7 & 11,9 & 16,4 & 12,9 & 11,4 & 30,3 & 25,1 \\
\hline Min. & 178,0 & 63,0 & 38,0 & 30,0 & 4,0 & 32,5 & 3,7 & 5,0 \\
\hline Maks. & 189,5 & 84,5 & 58,0 & 59,0 & 6,2 & 47,2 & 9,1 & 10,5 \\
\hline
\end{tabular}

1 lentelè. Lietuvos slidininkų ir biatlonininkų fizinio išsivystymo, raumenu, riebalų masès, jų santykio (RRMI) rodikliai 


\begin{tabular}{|l|c|c|c|c|c|c|c|c|}
\hline \multirow{2}{*}{ Rodikliai } & \multicolumn{2}{c}{ VRSG } & \multicolumn{2}{c|}{ AARG } & \multicolumn{2}{c|}{ 10 s } & \multicolumn{2}{c|}{ AGP 1 min } \\
\cline { 2 - 9 } & $\mathbf{W}$ & $\mathbf{W} / \mathbf{k g}$ & $\mathbf{W}$ & $\mathbf{W} / \mathbf{k g}$ & $\mathbf{W}$ & $\mathbf{W} / \mathbf{k g}$ & $\mathbf{W}$ & $\mathbf{W} / \mathbf{~ k g}$ \\
\hline$\overline{\mathrm{X}}$ & 1855,4 & 25,2 & 1240,3 & 16,7 & 878,1 & 11,7 & 469,5 & 6,3 \\
\hline $\mathrm{S} \overline{\mathrm{X}}$ & 98,7 & 1,0 & 40,1 & 0,3 & 33,8 & 0,3 & 19,0 & 0,1 \\
\hline $\mathrm{S}$ & 382,3 & 3,9 & 155,4 & 1,1 & 131,1 & 1,0 & 73,7 & 0,6 \\
\hline V, \% & 20,6 & 15,6 & 12,5 & 6,6 & 14,9 & 8,6 & 15,7 & 9,1 \\
\hline Min. & 1191,1 & 17,6 & 994,4 & 15,4 & 616,0 & 9,6 & 351,0 & 5,1 \\
\hline Maks. & 2543,2 & 30,6 & 1557,4 & 18,6 & 1060,0 & 13,0 & 600,0 & 7,3 \\
\hline
\end{tabular}

2 lentelè. Lietuvos slidininkų ir biatlonininku fizinio pajègumo rodikliai

\begin{tabular}{|c|c|c|c|c|c|c|c|c|c|}
\hline \multirow[b]{2}{*}{ Rodikliai } & \multicolumn{5}{|c|}{ Kritinė intensyvumo riba } & \multicolumn{4}{|c|}{ Anaerobinio slenksčio riba } \\
\hline & $\begin{array}{c}\text { PV, } \\
1 / \text { min }\end{array}$ & $\begin{array}{l}V_{2_{\text {max }}}, \\
1 / \text { min }\end{array}$ & $\begin{array}{c}\mathrm{VO}_{2 \max }, \\
\mathrm{ml} / \mathrm{min} / \mathrm{kg}\end{array}$ & $\mathbf{W}$ & $\begin{array}{l}\text { PV, } \\
\text { 1 / min }\end{array}$ & $\begin{array}{l}\mathrm{VO}_{2} \\
\mathrm{l} / \mathrm{min}\end{array}$ & $\begin{array}{c}\mathrm{VO}_{2} \\
\mathrm{ml} / \mathrm{min} / \mathrm{kg}\end{array}$ & W & RI \\
\hline$\overline{\mathrm{X}}$ & 152,2 & 4,9 & 65,8 & 358,0 & 101,1 & 4,0 & 54,8 & 290,7 & 3,7 \\
\hline $\mathrm{S} \overline{\mathrm{x}}$ & 8,2 & 0,2 & 2,1 & 7,3 & 4,4 & 0,1 & 1,6 & 10,3 & 0,6 \\
\hline $\mathrm{S}$ & 31,8 & 0,6 & 8,0 & 28,1 & 16,9 & 0,4 & 6,1 & 39,9 & 2,3 \\
\hline $\mathrm{V}, \%$ & 20,9 & 12,2 & 12,1 & 7,8 & 16,7 & 10,4 & 11,2 & 13,7 & 60,9 \\
\hline Min. & 106,0 & 3,9 & 54,3 & 290,0 & 81,0 & 3,2 & 44,8 & 170,0 & 0,0 \\
\hline Maks. & 206,7 & 6,3 & 80,0 & 410,0 & 144,6 & 4,5 & 67,5 & 340,0 & 9,2 \\
\hline
\end{tabular}

3 lentelè. Lietuvos slidininkų ir biatlonininkų aerobinio pajègumo rodikliai

vos slidininkų absoliutus AGP siekè vidutiniškai $469,5 \pm 19,0 \mathrm{~W}$, o santykinis - 6,3 $\pm 0,1 \mathrm{~W} / \mathrm{kg}$ (sklaida nedidelè - V =9,1\%). Tenka pažymèti, kad tirtų sportininkų absoliutaus AGP sklaidos plotas - nuo 351 iki $600 \mathrm{~W}$.

Labai svarbią informaciją apie sportininkų organizmo adaptaciją prie fizinių krūvių teikia aerobinio pajègumo rodikliai ties kritinio intensyvumo ir anaerobinès apykaitos slenksčio ribomis. Nustatyta, kad tirtų Lietuvos slidininkų ir biatlonininku santykinis $\mathrm{VO}_{2 \max }$ rodiklis yra $65,8 \pm 2,1 \mathrm{ml} / \mathrm{kg}$ $(\mathrm{V}=12,1 \%)$. Ties anaerobinès apykaitos slenksčio riba $\mathrm{VO}_{2}$ siekia $54,8 \pm 1,6 \mathrm{ml} / \mathrm{kg}(\mathrm{V}=11,2 \%)$. Atliekamo darbo galingumas ties šiomis ribomis buvo $358,0 \pm 7,3$ ir $290,7 \pm 10,3 \mathrm{~W}$ (3 lent.).

Tirtų sportininkų kraujotakos ir kvėpavimo sistemos funkcini pajègumą nusakantis Rufjè indekso rodiklio vidurkis buvo $3,7 \pm 0,6$. Šio rodiklio procentinè sklaida labai didelè $(\mathrm{V}=60,9 \%)$. Sklaidos plotas - 9 vienetai.

\section{REZULTATUQ APTARIMAS}

Tyrimo rezultatų koreliacinè analizè parodè, kad tarp sportininkų bendrosios kūno, raumenų masès ir raumenų galingumo, atliekant ịvairios trukmès krūvị, yra glaudūs koreliaciniai ryšiai (4 lent.). Raumenų mase turi tiesioginius patikimus ryšius su absoliučiaisiais VRSG $(\mathrm{r}=0,705)(\mathrm{p}<0,01)$ ir AARG $(\mathrm{r}=0,870)(\mathrm{p}<0,001)$ rodikliais, $\mathrm{su}$ absoliučiuoju AGP $(r=0,878)(p<0,001)$, su atliekamo darbo galingumu ties KIR $(r=0,643)$ $(\mathrm{p}<0,01)$. Analogiškus tyrimo rezultatus gavo ir S. Grashill ir kt. (1999), L. Tubelis ir kt. (2006). Šie autoriai, taip pat ir U. Bergh ir G. Forsberg (1992) pažymi glaudų koreliacini ryši tarp VRSG ir AARG. Atlikto tyrimo duomenys taip pat rodo glaudų koreliacinị ryši tarp šių rodiklių $(r=0,701)$ ir labai glaudu AARG ryši su $10 \mathrm{~s}$ trukmès darbo galingumu $(\mathrm{r}=0,851)$. Kaip pažymi V. Rybakovas ir kt. (Рыбаков и др., 1995), T. S. Timakova (1996), labai svarbus organizmo funkciniu galių rodiklis yra slidininkų glikolitinio pajėgumo lygmuo. Atlikto tyrimo metu nustatyta, kad šis rodiklis glaudžiai siejasi su deguonies suvartojimu ties anaerobinio slenksčio riba $(r=0,706)$. Tai reiškia, kad ugdant aerobini pajègumą yra veikiamas ir anaerobinis glikolitinis pajëgumas. Kai kurie tyrèjai (Berg, Forsberg, 1992) mano, kad lengvesnio svorio slidininkų maksimalusis deguonies suvartojimas vienam kilogramui kūno masès yra didesnis negu sunkesniu slidininku, bet analizuojant pajègiausiuju pasaulio slidininku kūno masès rodiklius galima pastebèti, kad jie yra sunkesni nei mažesnio meistriškumo sportininkai. Tyrimas parodé, kad net ir tada, kai tiriamujų kūno masès sklaida maža $(\mathrm{V}=9,7 \%)$, patikimo koreliacinio ryšio tarp kūno masès ir $\mathrm{VO}_{2 \max }$ nenustatyta $(\mathrm{r}=0,409)(\mathrm{p}>0,05)$. Tarp $\mathrm{VO}_{2 \max }$ ir deguonies suvartojimo ties anaerobinio slenksčio riba buvo stiprus koreliacinis ryšys $(r=0,793)(p<0,001)$. Netikèta buvo tai, kad aptiktas patikimas kraujota- 
4 lentelè. Lietuvos slidininkų ir biatlonininkų fizinio išsivystymo, fizinio pajègumo ir aerobinio pajègumo rodiklių koreliaciniai ryšiai

\begin{tabular}{|c|c|c|c|c|c|c|c|c|c|c|c|c|c|c|c|c|c|}
\hline & \multirow{2}{*}{\multicolumn{3}{|c|}{ Fizinis išsivystymas }} & \multirow{2}{*}{\multicolumn{8}{|c|}{ Fizinis pajėgumas }} & \multicolumn{6}{|c|}{ Aerobinis pajègumas } \\
\hline & & & & & & & & & & & & & KIR & & & NS & \\
\hline & \multirow{2}{*}{$\begin{array}{c}\text { Ūgis, } \\
\text { cm }\end{array}$} & \multirow{2}{*}{$\begin{array}{c}\text { Kūno } \\
\text { masé, } \\
\text { kg }\end{array}$} & \multirow{2}{*}{$\begin{array}{c}\text { Rau- } \\
\text { menų } \\
\text { masé, } \\
\text { kg }\end{array}$} & \multicolumn{2}{|c|}{ VRSG } & \multicolumn{2}{|c|}{ AARG } & \multicolumn{2}{|c|}{$10 \mathrm{~s}$} & \multicolumn{2}{|c|}{ AGP 1 min } & \multirow{2}{*}{$\begin{array}{c}\text { PV, } \\
\mathbf{l} / \mathrm{min}\end{array}$} & \multirow{2}{*}{$\begin{array}{c}\mathrm{VO}_{2 \max } \\
\mathrm{ml} / \mathrm{min} / \mathrm{kg}\end{array}$} & \multirow[b]{2}{*}{$\mathbf{W}$} & \multirow{2}{*}{$\begin{array}{c}\text { PV, } \\
\mathbf{l} / \mathrm{min}\end{array}$} & \multirow{2}{*}{$\begin{array}{c}\mathrm{VO}_{2,}, \\
\mathrm{ml} / \mathrm{min} / \mathrm{kg}\end{array}$} & \multirow{2}{*}{ RI } \\
\hline & & & & W & W / kg & $\mathbf{W}$ & W / kg & W & W / kg & $\mathbf{W}$ & W / kg & & & & & & \\
\hline & 1 & 2 & 3 & 4 & 5 & 6 & 7 & 8 & 9 & 10 & 11 & 12 & 13 & 14 & 15 & 16 & 17 \\
\hline 1 & 1 & & & & & & & & & & & & & & & & \\
\hline 2 & 0,620 & 1 & & & & & & & & & & & & & & & \\
\hline 3 & 0,535 & 0,986 & 1 & & & & & & & & & & & & & & \\
\hline 4 & 0,151 & 0,648 & 0,705 & 1 & & & & & & & & & & & & & \\
\hline 5 & $-0,283$ & 0,197 & 0,287 & 0,837 & 1 & & & & & & & & & & & & \\
\hline 6 & 0,477 & 0,850 & 0,870 & 0,701 & 0,407 & 1 & & & & & & & & & & & \\
\hline 7 & $-0,030$ & 0,159 & 0,218 & 0,389 & 0,497 & 0,652 & 1 & & & & & & & & & & \\
\hline 8 & 0,383 & 0,846 & 0,878 & 0,754 & 0,449 & 0,851 & 0,391 & 1 & & & & & & & & & \\
\hline 9 & $-0,097$ & 0,310 & 0,380 & 0,557 & 0,560 & 0,508 & 0,530 & 0,760 & 1 & & & & & & & & \\
\hline 10 & 0,502 & 0,862 & 0,873 & 0,701 & 0,276 & 0,630 & $-0,061$ & 0,805 & 0,368 & 1 & & & & & & & \\
\hline 11 & 0,202 & 0,429 & 0,466 & 0,533 & 0,242 & 0,194 & $-0,266$ & 0,468 & 0,290 & 0,809 & 1 & & & & & & \\
\hline 12 & $-0,018$ & 0,573 & 0,633 & 0,523 & 0,398 & 0,635 & 0,388 & 0,508 & 0,216 & 0,378 & 0,042 & 1 & & & & & \\
\hline 13 & $-0,270$ & $-0,409$ & $-0,405$ & $-0,123$ & 0,123 & $-0,239$ & 0,099 & $-0,450$ & $-0,312$ & $-0,538$ & $-0,471$ & $-0,122$ & 1 & & & & \\
\hline 14 & 0,290 & 0,681 & 0,643 & 0,266 & $-0,036$ & 0,457 & $-0,112$ & 0,463 & $-0,011$ & 0,507 & 0,085 & 0,559 & $-0,010$ & 1 & & & \\
\hline 15 & $-0,111$ & 0,320 & 0,368 & 0,215 & $-0,004$ & 0,073 & $-0,294$ & 0,297 & 0,135 & 0,492 & 0,545 & 0,519 & $-0,595$ & 0,299 & 1 & & \\
\hline 16 & $-0,483$ & $-0,725$ & $-0,718$ & $-0,429$ & $-0,050$ & $-0,602$ & $-0,106$ & $-0,658$ & $-0,324$ & $-0,706$ & $-0,472$ & $-0,247$ & 0,793 & $-0,153$ & $-0,368$ & 1 & \\
\hline 17 & $-0,145$ & $-0,105$ & $-0,043$ & $-0,109$ & 0,135 & 0,148 & 0,431 & $-0,055$ & 0,064 & $-0,381$ & $-0,557$ & 0,318 & 0,355 & $-0,068$ & $-0,297$ & 0,271 & 1 \\
\hline
\end{tabular}

Pastaba. $\mathrm{p}<0,05$, kai $\mathrm{r}=0,497-0,605 ; \mathrm{p}<0,01$, kai $\mathrm{r}=0,606-0,715 ; \mathrm{p}<0,001$, kai $\mathrm{r}=0,716$ ir daugiau.

kos ir kvėpavimo sistemos funkcinio pajègumo rodiklio Rufjè indekso ryšys su santykiniu anaerobiniu glikolitiniu pajėgumu $(r=0,557)(p<0,05)$.

\section{IŠVADA}

Apibendrinant tyrimo rezultatus galima pažymèti, kad Lietuvos slidininkų ir biatlonininkų fizinių ir funkciniu galių rodikliai yra daugiau vidutinio lygio, lyginant juos su pajėgiausiujų žiemos šaku sportininkų duomenimis (Čepulènas, 2004). Pasiekus tik vidutinio lygio anaerobini glikolitini pajègumą ir aerobini pajègumą ties kritinio intensyvumo riba sunku tikètis geresnių rezultatų tarptautinèse varžybose. Taigi šio tyrimo metu gauta informacija gali padèti tobulinti tolimesnį Lietuvos žiemos šaku sportininkų rengimą, nukreipiant jų fizinių ir funkcinių galių ugdymą reikiama linkme.

\section{LITERATŪRA}

Bergh, U., Forsberg, G. (1992). Influence of body mass on cross-country ski racing performance. Medicine and Science in Sports and Exercise, 24 (9), 1033-1039.

Bompa, T. P. (1994). Theory and Methodology of Training the Key to Athletic Performance. Kendal Hunt Publishing. Bosco, C., Wiitsalo, J. V., Komi, P. V., Luchtanen, P. (1982). Combined effect of elastic energy and myoelectrical potention during stretch-shortening cycle exercise. Acta Physiologica Scandinavica, 114, 558-565.

Byrnes, W. C., Kearnary, J. T. (1997). Aerobic and anaerobic contributions during simulated canoe / kayak invents. Medicine and Science in Sports and Exercise, 29 (5), $220-225$.

Čepulėnas, A. (2006). Lietuvos olimpinės slidinėjimo rinktinès treniravimo ypatumai slidinejjimo pratybų mezociklais vasaros ir rudens laikotarpiu. Sporto mokslas, 1 (43), 78-74.

Čepulènas, A. (1997). Olimpinès čempionès Vidos Vencienès pasirengimo Kalgario žiemos olimpinèms žaidy- nėms pedagoginè charakteristika. Sporto mokslas, 3 (8), 26-32.

Čepulėnas, A. (2004). Slidininkų lenktynininkų Solt Leik Sičio žiemos olimpinių žaidynių dalyviu amžius, kai kurių somatinių rodiklių ir sportinių rezultatų lyginamoji analizè. Sporto mokslas, 1 (35), 18-24.

Čepulènas, A. (2001). Slidininku rengimo technologija. LKKA.

Grashill, S. E., Serfass, R. C., Bacharach, D. W., Kelly, J. M. (1999). Responses to training on cross-country skiers. Medicine and Science in Sport and Exercise, 31 (8), 1211-1217.

Grund, A., Krause, M., Kraus, M. (2001). Associate between different attributes of physical activity and mass in untrained, endurance and resistance-trained man. European Journal Applied Physiology, 84, 310-320.

Hottenrott, K., Urban, V. (1998). Handbuch für Skilanglauf. Aachen: Meyer and Meyer.

Mäestu, J., Jürimäe, J., Jürimäe, T. (2005). Monitoring 
of performance and training in rowing. Sports Medicine, 35 (7), 597-617.

Margaria, R., Aghemo, P., Rovelli, E. (1966). Measurement of muscular power (anerobic) in man. Journal of Applied Physiology, 21, 1661-1664.

Milašius, K., Raslanas, A., Skernevičius, J. (1998). Lietuvos slidininkų pasirengimo Nagano olimpinèms žaidynėms analizè. Sporto mokslas, 2 (11), 25-32.

Nowacki P. (1978). Dir Bedeufung der modernen kardiorespiratorische Functions diagnostic für jugendliche Lerstungssportler und ihre Trainer. Sportärtliche und Sportpëdagogische Betreinung zur Sportmedizin, 8, 153178.

Rusko, H. (2003). Physiology of cross country skiing. In H. Rusko (Ed.), Handbook of Sports Medicine and Science Cross-country Skiing (pp. 1-31). Blackwell Science.

Skernevičius, J., Raslanas, A., Dadelienè, R. (2004). Sporto mokslo tyrimu metodologija. Vilnius: LSIC.
Street, G. M., Gregory, R. W. (1994). Relationship between glide speed and Olympic cross-country ski performance. Journal of Applied Biomechanics, 10, 393-399.

Szögy, A., Cherebetin, G. (1979). Minuten Test auf dem Fahradergometer zur Bestimmung der anaerobien $\mathrm{Ca}-$ pazitat. European Journal of Applied Physiology, 33, $171-176$.

Timakova, T. S. (1996). Typological classification of Russian Olympic skiers. Biology of Sport, 13 (3), 221-232.

Tubelis, L., Skernevičius, J., Milašius, K., Dadelienė, R. (2006). Didelio meistriškumo ivvairių sporto šakų sportininkų fizinio išsivystymo, fizinio ir funkcinio pajègumo adaptaciniai ypatumai. Sporto mokslas, 3 (45), 60-66.

Рыбаков, В. В., Куликов, Л. М. (1995). Особенности проявления взаимосвязи задаваемых нагрузок и адаптационных реакций в организме квалифицированных лыжников-гонщиков. Теория и практика физической культуры, 4, 47-50.

\title{
CORRELATION AND COMPARATIVE ANALYSIS OF PHYSICAL AND FUNCTIONAL ABILITIES OF LITHUANIAN SKIERS AND BIATHLETES
}

\author{
Stanislav Sabaliauskas, Kazys Milašius \\ Vilnius Pedagogical University, Vilnius, Lithuania
}

\begin{abstract}
An adequate assessment of athletes' special performance and functional abilities at any time-span of the preparatory period is one of the topical problems in diagnosing physical and functional capacity of athletes. The indices of skiers and biathletes' bodily performance and functional abilities may correlate with physical development indices. Analysis of the interrelation between these indices highlights the features that are highly significant for skiers and biathletes striving for high results.

The aim of the work was to investigate the characteristics of physical development, physical abilities and certain functions of Lithuanian skiers and biathletes, to perform their comparative analysis and to elucidate their interrelation.

The methods of the study were as follows: the basic indices of physical development were determined, physical capacity was assessed according to the absolute and relative single muscular contraction power, anaerobic alactic power, anaereobic glycolytic and aerobic capacity were assessed, too. Methods of mathematical statistics were applied for data processing.

A close correlation was found among the athletes' total body mass, muscular mass and muscular power performing physical loads of different duration. Muscular mass showed a reliable direct correlation with absolute SMCP $(r=0.705)$ and AAMP $(r=0.643)$. Our data also revealed a close correlation between SMCP and AAMP $(r=0.701)$ and a very close relation of AAMP to 10 -s working capacity $(r=0.851)$. Given an insignificant body mass data dispersion $(\mathrm{V}=9.7 \%)$, no reliable correlation was found between body mass and $\mathrm{VO}_{2 \max }(\mathrm{r}=0.401)$. There was a strong correlation between $\mathrm{VO}_{2 \max }$ and $\mathrm{VO}_{2}$ at the anaerobic threshold limit $(\mathrm{r}=0.743)$.

The summarized data revealed that the physical and functional capacity indices of Lithuanian skiers and biathletes were mostly of the medium level compared to the respective indices of their top-class counterparts. Therefore the information obtained in the present study may contribute to improving the preparatory process of Lithuanian skiers and biathletes and training their physical and functional abilities as desired.
\end{abstract}

Keywords: physical development, physical abilities, coefficient of correlation.

Gauta 2007 m. sausio 5 d.

Received on January 5, 2007

Priimta 2007 m. lapkričio 15 d.

Accepted on November 15, 2007

\section{Stanislav Sabaliauskas}

Vilniaus pedagoginis universitetas

(Vilnius Pedagogical University)

Studentu g. 39, LT-08106 Vilnius

Lietuva (Lithuania)

Tel +370 52734858

E-mailkazys.milasius@vpu.lt 